\title{
MALIGNANT ADENOMYOEPITHELIOMA OF THE BREAST: CASE REPORT AND LITERATURE REVIEW
}

Luana Grazielle dos Santos Ferreira', Lilian de Sá Paz Ramos

${ }^{1}$ Hospital Aristides Maltez - Salvador (BA), Brazil.

Introduction: Adenomyoepithelioma of the breast is a rare, malignant, biphasic tumor of low grade, usually found in older women. Cases of metastasis are unusual, and when they occur, the most common sites are the lungs, brain, and thyroid. Clinical case: We discussed the case of a 49-year-old female patient with mammography and breast ultrasound showing a solid lesion, with ill-defined margins in the left breast. Excisional biopsy was performed, and the histological analysis confirmed the diagnosis of malignant adenomyoepithelioma with focally involved surgical margins. The treatment chosen was mastectomy with immediate reconstruction. Conclusion: The course and prognosis of the disease are unclear. Local recurrence is common; however, complete excision with safety margins represent the most effective form of treatment. 